\title{
Structuring Uncertainty and Conflicting Objectives for Life or Death Decisions Following an Urban Biological Catastrophe
}

\author{
Heather Rosoff ${ }^{1}$, Richard John ${ }^{2}$, William J. Burns ${ }^{3}$, and Robert Siko ${ }^{2}$ \\ Received: 01/10/2011 / Accepted: 30/06/2012 / Published online: 04/09/2012
}

\begin{abstract}
A large-scale biological terrorist attack would likely result in mass casualties and have major economic consequences for the affected area, and potentially for the nation as a whole. The extent to which an impacted area recovers from such losses depends in large part on the decision making of local residents. In this study we utilize scenario simulation, a methodology that uses video simulation of a news report to immerse respondents in the details and consequences of a biological terrorist attack. Specifically, we explore the decision-making of local residents to a large-scale terrorist attack using weaponized anthrax in the Seattle, Washington area. The scenario was based on one of the U.S. Department of Homeland Security's National Planning Scenarios. This study focuses on structuring a decision model around the objectives and motivations that shape local residents' decisions to act during recovery from an anthrax attack. The relevant uncertainties and objectives that drive residents' decisions during response and recovery from the anthrax attack were developed using group scenario simulations with various stakeholders in Seattle. In the beginning stages of the crisis concerns about health predominate. Later concerns about financial security emerge. Throughout it appears that residents weigh their concerns for safety with the collective costs of leaving the Seattle area. The decision model produces several key insights that are critical to the development and implementation of recovery policies. A causal loop diagram is also presented that depicts the dynamic nature of this decision process.
\end{abstract}

Key words: Terrorism; value focused thinking; objectives hierarchy; system dynamics modelling

\section{INTRODUCTION}

Of the perceived bioterrorism threats, the U.S. Department of Homeland Security has indicated that anthrax and smallpox are the two agents with the greatest potential for mass casualties and civil disruption (Kortepeter and Parker 1999). As evidenced by the 2001 Anthrax incidents in the U.S., these attacks caused widespread anxiety and required lengthy and costly remediation for contained, indoor areas. If left

\footnotetext{
${ }^{1}$ Sol Price School of Public Policy \& CREATE, University of Southern California, USA, rosoff@usc.edu

${ }^{2}$ Dept. of Psychology \& CREATE, University of Southern California, USA, richardj@usc.edu \& siko@usc.edu

${ }^{3}$ Decision Research, Eugene, OR, California State University, San Marcos, USA, william_burns@sbcglobal.net
} 
untreated, the death rate from anthrax infection would be expected to exceed $80 \%$. This result is exacerbated by the fact that anthrax is environmentally stable and known to survive for decades. Weaponized anthrax is also capable of aerosolized transmission and mass production. Iraq produced anthrax for use in Scud missiles, and the U.S. produced anthrax as part of a biological weapons research program until 1969 (Department of the Army 1977, Runge 2008). When properly weaponized this agent is invisible, odorless, tasteless, and easily re-aerosolized, presenting the potential to cause large disease outbreaks (Weis et al. 2002). These characteristics result in the delay of agent recognition, allowing for rapid spread of the agent, particularly if aerosolized and in an inhalation form (the most deadly form of anthrax infection) (Kortepeter and Parker 1999, Weis et al. 2002).

The 2001 U.S. anthrax attack and numerous drills for weapons of mass destruction have shown that it is difficult to prepare fully and respond completely to a large scale anthrax attack. There are inevitably direct costs to property and immediate effects on productivity, as well as longer term decontamination and clean-up costs. There are also ongoing effects on productivity, as well as indirect costs of the public responding to terrorism (Geisecke et al. 2012). To minimize lengthy and costly consequences of an anthrax attack, officials at local, state, and national levels must coordinate efforts to develop preparedness, response and recovery strategies.

To this end, the Interagency Biological Restoration Demonstration (IBRD) project was introduced in 2006 by the U.S. Department of Homeland Security (DHS) and the U.S. Defense Threat Reduction Agency (DTRA), part of the U.S. Department of Defense (DoD). Its central mission was to work with interagency organizations, including state and local representatives, to reduce the time and resources required to recover and restore wide urban areas, military installations, and other critical infrastructures following a biological incident. The Seattle urban area was selected as a demonstration region. Specifically, the exercise explored how to develop comprehensive guidance for restoration and recovery following an anthrax attack (DHS National Planning Scenario 2). The overall project consisted of four separate efforts designed to address the needs, capabilities, procedures and technology development required for recovery and restoration actions in Seattle. The project culminated with the IBRD Capstone Exhibition in Seattle, Washington on September 21-23, 2010 where stakeholders, partners, and other interested local and federal players were informed about advancements in wide-area recovery and remediation developed by the IBRD program.

A key component in the development of a recovery and remediation strategy is an understanding of how the public will react and respond to official recommendations during a major emergency. As disaster officials race to respond to the event, citizens impacted by the attack will formulate their own plans. They will assess the risk to themselves and their family and friends, the availability of goods and services, the availability of public health services, and the extent and quality of the government response, among other factors. Just as individuals will be looking to government officials for information on how to react, policy makers need to understand the public response to create behaviorally realistic policies (Fischhoff et al. 2003).

The perceived risk and decision making of the local citizenry introduces a critical set of influences on the long-term economic sustainability and prosperity of the region. Economic analyses typically focus on variables such as lives lost, impacts on domestic and global markets and defense and homeland security spending. In contrast, the focus of our research is on social and behavioral considerations, some of which are important inputs to traditional economic analysis. Is the impacted public concerned about their financial stability? What are their primary concerns relative to personal and health safety? In the aftermath of the attack, what is their psychological well-being - one of fear? anger? post-traumatic stress? The likely consequences might include people refraining from inhabiting, investing, working and/or shopping in affected and adjacent areas. These attitudes and behaviors may stigmatize an area in a way that is difficult for the affected region to overcome, even following complete decontamination (MorrowJones and Morrow-Jones 1991, Ichinosawa 2006, DeSalvo 2007, Yi Ge et al. 2011). 
Psychologists have worked primarily within a psychometric paradigm to explore the various factors of risk perception, and how these are related to attitudes and intended behaviors in particular contexts (Sjoberg, 1998, 2002, Alhakami and Slovic 1994, Engelberg and Sjoberg, 2005). Sociologists have worked primarily within a field research paradigm, conducting surveys and interviews with disaster survivors, to capture retrospective memories about survivors' thoughts and emotions during the course of the disaster and to relate these to both disaster preparedness and behaviors actually engaged in during the disaster (Tierney 1989, 1999, 2007, 2008, Tierney et al. 2006). Both approaches have limitations. Researchers using the psychometric paradigm typically rely on respondents' reactions and predictions related to hypothetical events in a static context, and rarely ask respondents to react to an evolving disaster event. Researchers employing post-disaster field surveys and interview methods typically rely on the potentially faulty memories of their respondents, who are also susceptible to social desirability biases.

Furthermore, most risk perception studies have focused on evaluating affective and cognitive components of public reactions and behavioral responses to disasters (Slovic et al. 2005, Wardman 2006, Slovic and Peters 2006, Västfjäll et al. 2008, Smith et al. 2009, Rosoff et al. 2011, Rosoff et al. 2012). Our emphasis is on the causal role of public values and beliefs in post attack decision-making and behavior. Of particular interest is the decision problem of when residents will decide to leave Seattle during the immediate attack response, and whether residents will return to Seattle or move away from Seattle during recovery.

We present the development, implementation and results of a scenario simulation experiment that uses video simulation of a series of local news reports to immerse respondents in the developing details of an anthrax attack in Seattle. The unfolding scenario is presented in discrete episodes, allowing us to track responses over the simulated time period and evaluate changes in decision making about whether or not to remain in the Seattle area during the response and recovery phases of the disaster. Seattle residents and business members were recruited to participate in group exercises that take participants through an anthrax attack scenario. Respondents are invited to articulate their thoughts and feelings amidst the escalating crisis. The sessions included prompts designed to identify participants' uncertainties, objectives, and possible action alternatives. The goal of the simulation is to immerse participants in the images and emotions surrounding an actual anthrax attack, and to elicit their beliefs, emotions, and intentions to act while they are "in the moment" of the unfolding crisis. This research design focuses subjects' attention on the details of the scenario, and controls for extraneous variables that might influence their responses spread over the 2-year simulated period. More specifically, we explore how the study design might provide additional insight into the following research questions:

1. Will Seattle residents opt to remain, leave permanently, or leave and return to the affected area as a consequence of the attack?

2. What are the personal considerations (e.g. financial, social, and political) that influence the decisions of the public and business communities to stay or leave the area?

3. How do personal considerations change over the course of the recovery period following the anthrax attack?

There is a need for a methodological approach that can be used to assess the uncertainty associated with the decision making of the general population when faced with a large-scale disaster. A greater understanding of the resident values can help accurately forecast post-attack decision making. Accurate forecasting of residents' post-event decision making and behavior is critical to policy making during response and recovery to terrorist related events, and in particular biological attacks.

We begin with a summary of the study design, which includes details about participants, the scenario simulation design, and group exercise procedures. Next we describe the reactions to the simulated anthrax attack in narrative form. Information from the scenario simulation group exercises were then used to construct two influence diagrams (Shachter 1986, Howard and Matheson 2005, Howard 2007) summarizing public uncertainties, objectives, and choices during the attack response and recovery phases. 
In addition, we constructed a causal loop diagram (Sterman 2004, Ford 2009) depicting the dynamics related to public beliefs and behavior during the response and recovery from the simulated anthrax attack. We conclude with a discussion of the implications of our findings for risk managers, policy makers and risk researchers.

\section{STUDY DESIGN}

In order to formulate an understanding of how Seattle residents make critical decisions at various points in time following an anthrax attack, we conducted a brief survey to identify volunteers from the Seattle area interested in participating in a scenario simulation group exercise. Details about the survey design and the survey sample background and demographic information are included in Appendix A. In addition, we were interested in identifying members of Seattle's business community to participate in the scenario simulation group exercises. Information about business member recruitment is also included in Appendix A.

For the group exercises we developed a scenario simulation of a deadly anthrax release by terrorists in the Seattle area based on PNNL's "Seattle-Tacoma Urban Area Anthrax Incident: Long-Term Recovery Tabletop Exercises" used as part of IBRD. In the form of video news broadcasts, the scenario progresses over eight delineated episodes, spanning a 2 year period, and including a total of 54,000 deaths resulting from anthrax infection. A summary of scenario development and storyline is provided in Appendix B.

Also for the group exercises, we organized the sessions to be conducted in a similar format that would allow for consistency in the acquisition of information. A description of how the scenario simulation group exercises were structured and carried out is available in Appendix C.

\section{RESULTS}

Respondents' perceptions of risk and livelihood concerns, indicators of recovery, and economic incentives to return to the affected region are summarized separately for the Seattle Public and Seattle Business Groups. The results for the Seattle Business Groups are further broken down into two subsections; the first reflects their personal reactions to the event as business leaders in the area, and the second describes their perception of how they expect others to respond (businesses, government, and the general public). Risk perception and livelihood concerns refer to the values and objectives respondents identified as being important to their decision making at the various stages following the anthrax attack. Respondents also identified information within the scenario they felt was indicative of Seattle's economic and social recovery and discussed how this might affect their personal decision-making; the findings are reported in the indicators of recovery sub-section. Lastly, reactions to the various economic incentives introduced by researchers during group discussions to gauge the extent to which policy initiatives might influence Seattle residents' decisions to stay or return to the impacted region are described in the section on economic incentives to return. As mentioned in the previous section, respondents viewed an attack scenario that described events unfolding over a two-year period; hence, the discussion of respondent reactions is consistent with the attack aftermath timeline.

\section{Seattle Public Groups}

\section{Risk Perception and Livelihood Concerns}

In the immediate aftermath of the attack, participants' concerns were focused on short-term issues 
related to basic health, safety and security, including access to treatment and drug resistance to anthrax, as well as the availability of essential services such as food and water. Respondents interested in leaving Seattle were most concerned about their personal safety and that of their family and friends, as well as ensuring that they survived the anthrax attack. The duration of their departure was not a prioritized consideration at this stage of the attack. Respondents electing to remain in Seattle recognized a need to be sensitive to and aware of the attack events. Members of this latter group were less willing to seek out antibiotic treatment. Lastly, participants suffering from pre-existing medical conditions recognized that they would have less flexibility in their decision making and would likely remain in Seattle.

After the initial anthrax scare died down, participants who had left Seattle began considering whether they would return. They questioned their own safety and that of their families, particularly their children (when applicable) from ongoing anthrax exposure. Job security also was raised as a critical issue. Depending on the duration of their time away from the city, coupled with the extent of damage to the city, there was considerable uncertainty about how long Seattle area-based jobs would be available. A negative stigma about the region emerged, as participants discussed their comfort level with returning to a home or workplace once contaminated, visiting restaurants or stores decontaminated yet previously reported in hot zones, and simply walking down the street.

As the situation in Seattle continued to devolve, safety and health factors remained primary concerns for participants. Despite their high level of satisfaction with living in Seattle prior to the attack, respondents' decisions to return remained uncertain. Their decisions were strongly influenced by whether their families and friends wished to remain. Distrust in government also was raised, including feelings that authorities might falsely portray the city as "safe" due to economic pressures to repopulate the region. Participants certain they would not return to Seattle at this point were few. They were either university students who decided to complete their education elsewhere or persons who felt they would be resettled elsewhere before feeling safe enough to consider returning.

During the early stages of recovery, participants expressed their fears about civil disorder in Seattle and shortages of basic supplies such as food, medication, and water. Health concerns persisted with respect to antibiotic access, anthrax resistance, vaccine availability, and chances of exposure whenever outside their homes. Financial security emerged as increasingly important during discussions about surviving extended periods without work, providing financially for family members, and willingness to relocate to one of their company's other offices to retain employment. Quality of life concerns were expressed with respect to wandering around outside, tending gardens and generally avoiding latent anthrax exposure. This latter point is extremely critical to the livelihood of Seattle residents as many are drawn to the region for its seasonal outdoor recreational activities. Emotionally, participants reported stress, trauma, and grief. The extent of their affective responses varied depending on whether respondents' home or workplace was in a hot zone, whether respondents had lost loved ones, and respondents' perceived impact of the attack on their personal health, livelihood and happiness. Some participants continued to express lack of faith in federal, state, and local authorities to manage the anthrax crisis, and acknowledged that building trust in the government would be important to the success of Seattle's recovery.

\section{Indicators of Recovery}

At the outset of the attack, participants were able to identify specific factors that would influence their willingness to either stay or return to the Seattle area. These involved the liveability of the Seattle area including the overall functionality of the city, restoration of order, and presence of basic services such as food, water, and transportation.

As the scenario depicted Seattle a month after the attack, the livability of Seattle continued to be an important indicator of recovery. In addition, other signs of recovery important to the respondents were the 
extent and quality of decontamination procedures, whether smaller business stayed, and whether icons of the city, such as the professional sports teams, remained. Participants noted that if recovery was too slow, these indicators would hold less value over time. However, Seattle residents also felt that their ties and connections to the city provided reason to return, even if that return was years later.

Participants who said they would leave Seattle and were now still considering whether to return three months after the attack indicated they were basing their decision on whether there were fewer reports of anthrax exposure and deaths, evidence that clean-up was complete and that Seattle residents were returning to the region. When asked where they would obtain information about the attack recovery, participants indicated they would rely on news outlets and emergency responders, as well as monitor housing costs, job market numbers, and the return of small businesses.

\section{Business/Economic Incentives to Move Back}

In the immediate attack aftermath, participants were willing to remain in the areas surrounding the "hot zones" at a negotiated lower rent or mortgage rate. They were less comfortable engaging in daily activities, such as dining or holding a job, within a hot zone. Despite the appeal of economic incentives, participants were reluctant about putting their own and their family's health at risk. However, they were more open to considering federal programs that would subsidize housing in "hot zones" if vaccines or antibiotics were available.

As anthrax continued to affect Seattle, participants with strong ties to the region expressed a desire to contribute to the redevelopment of the regional economy even if their former job was not available. Also, participants in general felt that more affordable real estate and assistance with job placement were incentives to return. One group not receptive to incentives was students, who stated that a reduction in tuition did not influence their decision to return to the Seattle area for school or to complete school.

Two years following the attack, the economic incentives were less attractive to those who were living outside of Seattle. Former Seattle residents felt that if they had not returned to Seattle by this time, they would be less inclined to uproot from the new home and job they had created for themselves and their families.

\section{Seattle Business Groups - Personal Reactions}

\section{Risk Perception and Livelihood Concerns}

Similar to Seattle residents' responses in the immediate aftermath of the attack, business community representatives were primarily preoccupied with their personal health and well-being, and that of their families. There was also an imminent desire for assurance about the effectiveness of decontamination efforts, as participants cited relocating with their families to be a significant challenge.

Two years post attack, business group participants were looking for a returned sense of stability to the region, meaning no additional reported cases of anthrax infection and community confidence in the government's recovery plan. They also were interested in being educated about the ongoing risks of anthrax exposure to determine their next steps, while also expressing they might never feel comfortable returning to Seattle. The participants that elected to stay were willing to adapt their lifestyles to remain outside of the downtown area and take antibiotics every day for up to ten years. Those who preferred to relocate were uninterested in moving to another downtown area due to lingering concerns about their personal safety and that of their families.

Business group participants indicated that the return of basic services, such as food and water, was an essential indicator of recovery. Equally important was the restoration of banking and financial services, two factors critical to their daily business operations. 


\section{Business and Economic Incentives}

In the immediate attack aftermath, participants whose corporate office was in a hot zone expressed both a desire and need to relocate to a safer location. They acknowledged that relocation was a costly endeavor; therefore, a decision to move would likely be permanent. They indicated that their decision to leave would not be based on the business's survival alone, but rather on their sense of perceived risk and any other investments they might have, such as a home. Those participants not interested in relocating their businesses felt it would be important to offer additional benefits to employees who stayed, such as hazard pay for those who had to go into hot zone areas and information on living in post-attack Seattle.

When recovery was estimated to take longer than anticipated (months not weeks), participants felt their businesses were not equipped to survive such a strain. They indicated that the longer it took to redevelop Seattle, the less likely they would want to put their business back in Seattle as "Seattle would be a pariah."

\section{Seattle Business Groups - Expectations of Others’ Reactions}

\section{Risk Perception and Livelihood Concerns}

Group discussions about the weeks following the anthrax attack focused on how the business community would adapt to short-term disruptions. Overall, participants felt that there would be a general downward trend in Seattle as businesses and people departed, causing property and sales tax revenues to decrease. However, there were businesses identified (such as the regional medical centers and larger businesses like the ports and Microsoft) as able to sustain themselves amidst the crisis. For instance, one knowledgeable participant noted that the ports of Tacoma and Portland could likely cover most of the lost capacity from the Seattle Port in the short-term. Participants added that the businesses choosing to remain would create job opportunities, which in turn would contribute to making Seattle more attractive.

Two years post attack participants felt that the cost of business and living would be higher because of financial and psychological stigmas associated with the region. Yet they also believed that younger individuals, those without families, and those involved in the biotechnology industry would likely contribute to the survivability of Seattle.

When considering the livelihood of businesses specifically, participants felt that big businesses would benefit from collaborating with government leaders on Seattle's redevelopment plans. Government outreach was identified as critical to attracting companies to the Seattle area. Companies' were cited as important to drawing employees to the area through appealing benefits, perks, and extensive education and training about living in the redeveloped Seattle,. They also felt that people, especially the young, would still come to Seattle and that those individuals should be mobilized to take part in cleanup efforts.

\section{Indicators of Recovery}

Participants felt regular government communication about decontamination progress would be needed to mitigate perceptions that Seattle is unsafe, thereby improving business prospects in the region.

\section{Business and Economic Incentives}

Immediately following the attack, participants were particularly sensitive to the decision making of employees. They felt recently hired staff would be more likely to leave the area than their longer term employees. 
When recovery was estimated to take longer than anticipated (months not weeks), participants felt that the companies that could relocate, be duplicated, or conducted remotely would leave the city, while Seattle-specific businesses would remain.

When considering the vitality of their businesses two years post attack, participants stated that most companies would leave the area, particularly larger ones with financial flexibility. Smaller companies were perceived as unable to sustain themselves in Seattle, nor survive relocation. To encourage businesses to remain (if they had not left) or return to Seattle, they felt that extensive government support would be needed, such as tax breaks and other economic incentives. They also noted that Seattle, once a city attractive to smart and creative employees, would have trouble recruiting and retaining this same population.

\section{Conceptual Decision Model}

Using the information collected during the group discussion exercises, influence diagrams were developed to formalize the understanding and structure of the decision making of those impacted by the anthrax attack. To capture the change in decisions over time, two influence diagrams were developed; the first represents the decision context for Seattle residents within the first five days of the anthrax release, while the second represents the decision context during attack recovery, accounting for the period of 3 months to two years following the event. The influence diagrams illustrated herein describe the decision of Seattle's general public.

An influence diagram is a graphical representation of the structure of a decision problem (Shachter 1986, Howard and Matheson 2005, Howard 2007). The diagram consists of nodes and arcs used to capture the relationship among variables as well as represent a probabilistic description of the problem. The building blocks of the decision problem include: the decision nodes (represented as rectangles), uncertainty variables (represented as ovals), utility preference variables (represented as rounded rectangles), outcome variables (attributes, represented as hexagons), and overall utility node (represented as a box). Arcs into the variables represent probabilistic dependence. For example, an arc from an uncertainty node into an outcome node indicates that the probability distribution over possible outcomes is dependent on the uncertain variable. Arcs into decision nodes suggest that the information regarding previous decisions or the resolution of an uncertainty is available at the time of the decision. Lastly, the dashed arcs from one decision node into another capture the chronology of decision making.

\section{Short-Term Decision Model}

The influence diagram in Figure 1 describes uncertainties and objectives related to public decision making during the attack response phase (within the first five days following the attack). More specifically, the decisions Seattle residents are considering and the objectives and uncertainties relevant to those decisions are delineated.

From the Seattle public group discussions, researchers derived a set of personal outcome attributes relevant to decision making following the anthrax attack. These include: (1) personal safety, (2) financial security, (3) personal anthrax survival, and (4) family or friend anthrax survival. These 4 outcome attributes are represented as hexagons in Figure 1. The first outcome attribute refers to having access to basic services and goods, as well as the actual safety of the individual given public reaction to the attack. The second captures being in control of expenses and savings and having job security. The third and fourth are related to protecting oneself, and family and friends, from anthrax exposure and/or surviving anthrax infection with proper treatment and care. 


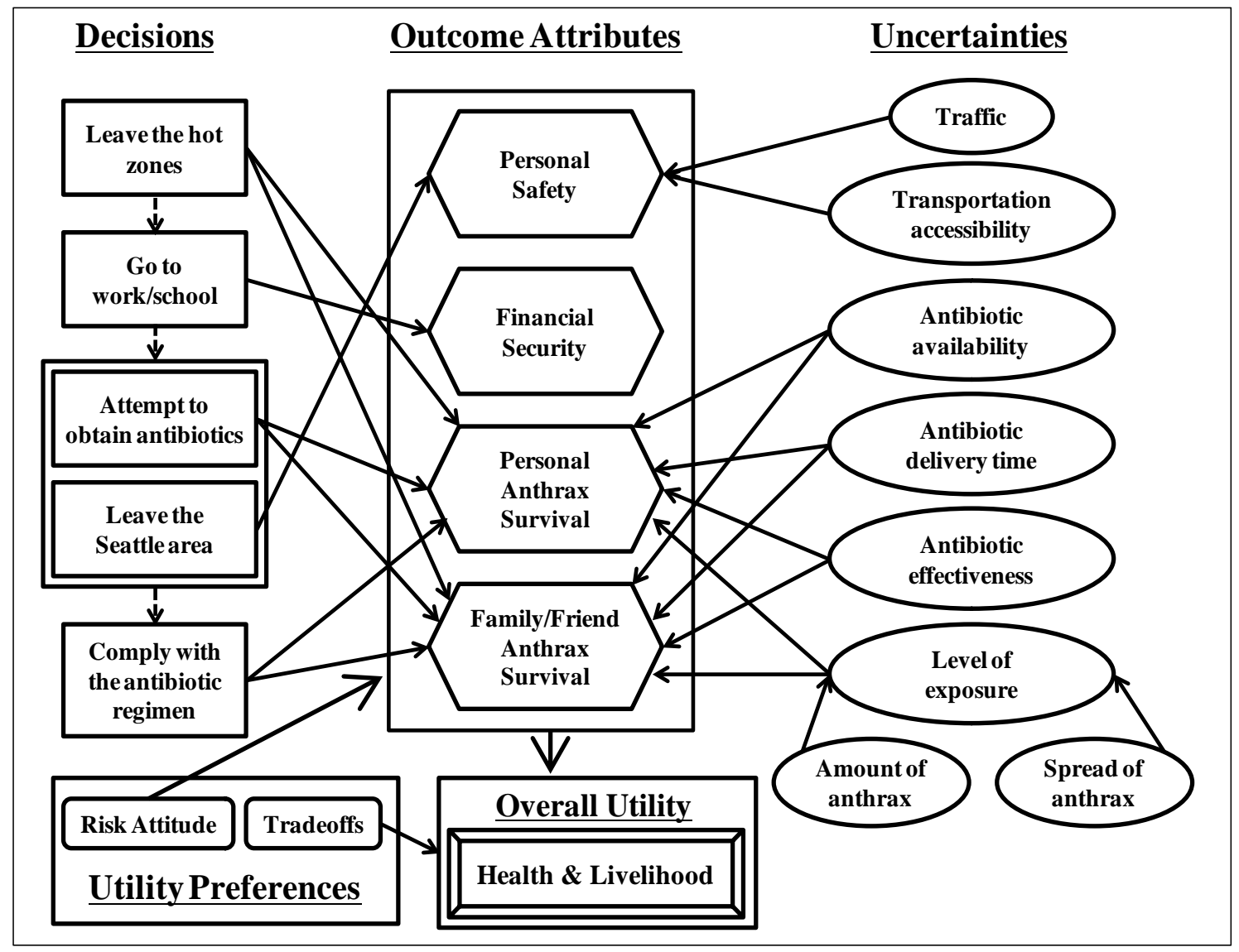

Figure 1. Influence diagram of the first 5 days following the anthrax attack

In addition, there are various details of the anthrax attack and response for which the public does not have perfect information, but are highly relevant for estimating the extent to which their personal outcomes are satisfied. These uncertainties are represented by ovals and the arcs connecting the nodes indicate a probabilistic dependency between the outcomes and an uncertain variable. With respect to anthrax survival (both personal and that of friends and family), the extent to which anthrax infections can be treated depends in large part on the availability of antibiotics and the vaccine, as well as whether the antibiotic is effective in treating the strain of anthrax released. There is little a Seattle resident can do to change their location at the time of the attack, and therefore there is a limit to what one can do to protect oneself from anthrax exposure. Personal safety is subject to the amount of traffic on the roads exiting the city, access to vehicles and gasoline for those requiring transportation, and other considerations related to local services such as police, fire, sanitation and food supply. Uncertainties pertaining to financial security are of limited concern at this point during the attack aftermath, as efforts are directed at health safety and survival.

In the aftermath of the attack, there are also certain critical decisions (represented as squares) that influence the extent to which the public's personal outcomes are met. Immediately following the first reports of the anthrax attack, Seattle residents are faced with decisions that directly impact their daily routines, including whether to leave the hot zones and continue going to work and/or school. These decisions, in turn, affect the extent of the public's satisfaction with outcomes relative to personal/family/friend anthrax survival and financial security, respectively. Once the consequences of the anthrax attack are further realized and understood, the public is likely to start considering whether to attempt to obtain antibiotics and leave the Seattle area. Whether an individual chooses to seek out 
treatment or leave the city first is a personal preference, hence the two decisions are boxed together as one. Both decisions are important considerations that the public will have to address, and hence must be taken before the subsequent decision of whether to comply with the antibiotic regimen.

Ultimately the overall utility node, labeled Health and Livelihood, represents the aggregation of public concerns relevant to the anthrax attack. In this case, Health and Livelihood represents the aggregated utility of personal safety, financial security, personal anthrax survival, and family/friend anthrax survival to Seattle residents. During group discussions it became clear that both tolerance of risk and priorities across outcomes vary over time and across different subsets of the population. These concerns are captured by the nodes labeled risk attitude and tradeoffs. For example, risk attitude might describe how a young family living just outside a hot zone is likely to be more risk averse and plan to leave the region compared to a single person who can afford to "wait and see" how the attack aftermath plays out. Tradeoffs refer to how this same young family is prioritizing personal survival of his/her family over the financial stability afforded through job security and other conflicting outcome attributes. Other differences in the population might be identified by demographic variables such as gender and income status, or alternatively by such factors as whether the Seattle resident is a business owner, lives or works in the hot zone, or has family in the region.

\section{Long Term Decision Model}

The influence diagram in Figure 2 describes the recovery phase of the anthrax attack at which point Seattle residents are deciding whether to return to Seattle during the 21 months period following the anthrax release (3 months to 2 years). Five outcome attributes (represented by octagons) were identified as capturing Seattle residents' preferences, of which three are the same as in Figure 1: personal safety, financial security, and personal anthrax survival. The two new values are psychological well-being and social appeal. Psychological well-being refers to Seattle residents' mental health and stability with respect to returning to the Seattle area and re-engaging in daily living activities. Social appeal refers to the attractiveness of the economic and social revitalization of the region.

During the recovery phase, the uncertainties (represented by ovals) surrounding the aftermath of the attack also shift. Concerns about anthrax survival continue to be sensitive to the ongoing availability of treatment options, but the extent and effectiveness of cleanup procedures is also important. Personal safety continues to be related to the provision of basic goods and services, and is now also conditional upon the region's social and economic vitality as it pertains to creating a secure environment for residents. This latter point refers to concerns such as whether the rebuilt Seattle is free of crime and danger often found in regions post-disaster. Financial security is contingent upon job opportunities, within and outside of the Seattle area, and the affordability of the city during recovery. Social appeal is subject to the attractiveness of the region's cultural revitalization. That is, Seattle residents will be wondering if they can once again take advantage of the city's climate and optimal location for year-round outdoor activities, follow the region's professional sports teams and seek out theatrical and musical performances in a region once recognized as a center for the performing arts. Psychological well-being refers to feelings related to post traumatic stress and stigmatizing impacts of the attack. The aforementioned uncertainty nodes are all characteristics of the values specific to the individual, and are not dependent upon the uncertainty of the attack outcome.

As noted, the critical decision at this phase of the attack aftermath is whether residents will return to Seattle. Prior to making this decision, the residents will have to decide whether to receive the anthrax vaccine and take the antibiotics to protect against residual anthrax exposure. The extent to which an individual is willing to take such precautionary measures affects outcomes relative to personal anthrax survival. Also, before deciding whether to return to Seattle, residents will have to address where they would prefer to live and work. Consideration of one's satisfaction with the financial gains afforded by a job, cultural attractiveness of a region, public safety, and livability of the region will be conditional upon 
such decisions.

In addition, the risk attitudes and tradeoffs are also included in Figure 2. As in Figure 1, the overall utility node labeled Health and Livelihood represents Seattle residents' objective function at any given point in time between 3 months and two years following the anthrax release.

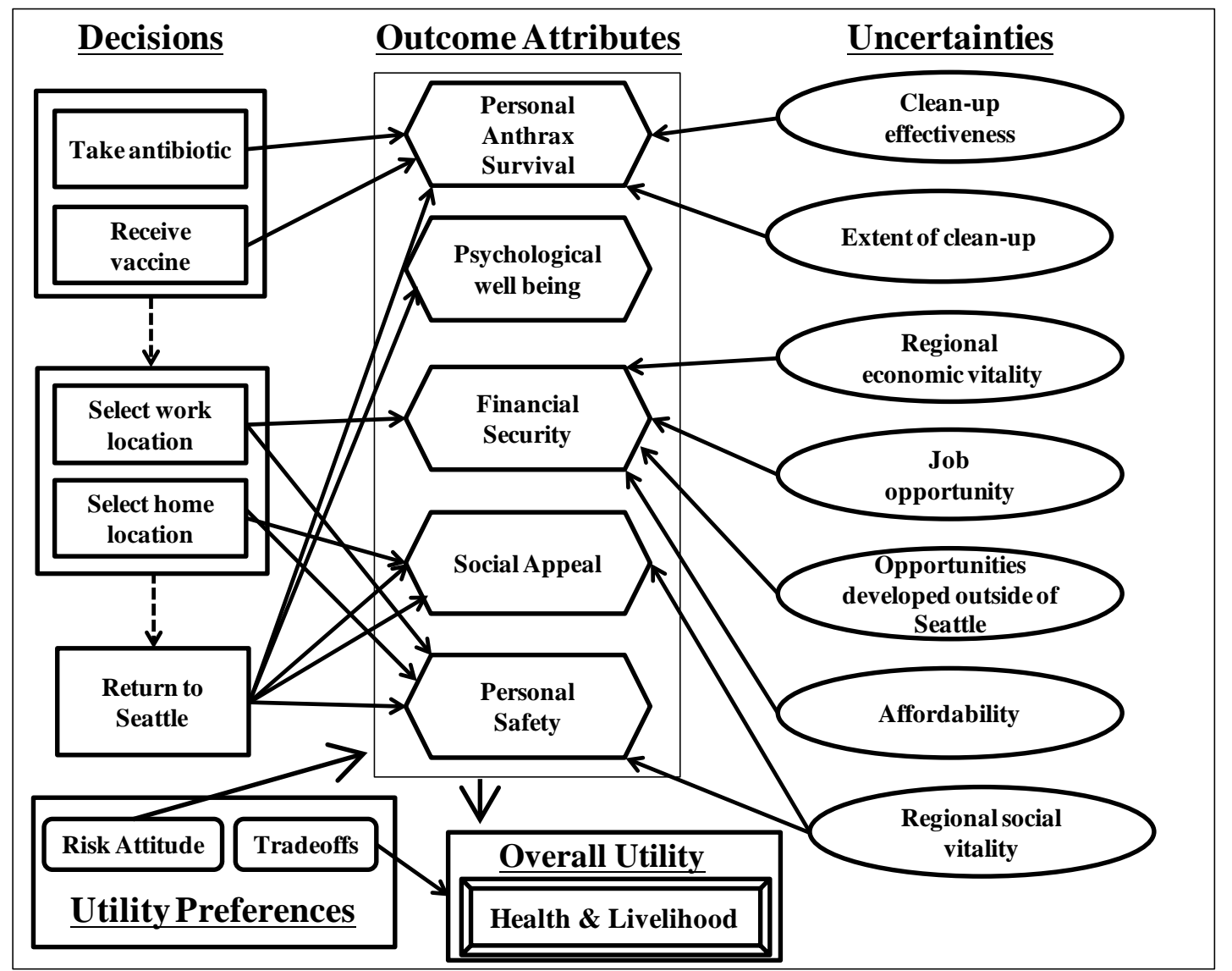

Figure 2. Influence diagram of the long term (3 months to 2 years) following the anthrax attack

\section{Causal Loop Diagram}

To better characterize the dynamic nature of the public decision process we constructed the causal loop diagram shown in Figure 3. This model is meant to complement the influence diagrams depicted in Figures 1 and 2. Directional arcs with signs connect variables and represent causal relationships (Sterman 2004, Ford 2009).

Following the discovery of an anthrax release in Seattle, hot zones would be identified, and an assessment would be made about the number of residents exposed. Official risk announcements would follow which would lead to widespread reporting through traditional and social media channels, and generate much concern among an individual's personal network (family, friends, co-workers). It would also lead to a rapid increase in dedicated resources to cope with the disaster including the distribution of antibiotics. Media coverage, concern in personal networks, efficacy of antibiotic treatment and eventually cleanup efforts would impact a person's assessment of threat. This threat assessment would be referenced against an individual's security comfort level (which may change during the crisis as a person adapts to this new threat level) creating a perceived security gap. However, security concerns would also be 
weighed against the cost of leaving Seattle. This cost would likely be a function of one's personal network within Seattle, financial security and opportunities outside of Seattle. The perceived livability of Seattle would also be important. The decision to leave Seattle until the crisis ends would involve a tradeoff between the increased security concerns and the cost of leaving. In some cases the perceived cost of leaving would be so small (an out-of-state college student) that even a minor concern with security could prompt a decision to leave Seattle. Conversely, in other cases the perceived cost of leaving would be so high (a person with a large extended family and no prospects for employment outside of Seattle) that even a grave security concern may not result in a decision to leave the city. In such instances an individual may opt to simply relocate within Seattle.

As news spreads that an antibiotic is available and effective, risk messages offer reassurance that the disaster is being managed, and individuals begin to adjust, an individual's perceived security gap should move toward pre-crisis levels. Experience across a variety of disasters suggests most people do not stay at a heightened state of concern indefinitely (Burns and Slovic 2007). However, if the economy of Seattle were to be severely disrupted and its livability diminished the now lower perceived cost of leaving the city may encourage people to move away from Seattle in increasing numbers. This would in turn, make it more difficult for the city to recover.

Those who have fled Seattle may at some point consider moving back. Naturally, they would continue to assess their level of threat and would monitor the progress and effectiveness of cleanup efforts. However, clean up efforts would take time (indicated by the hash marks on the corresponding arcs). During this time they would also be exposed to opportunities to build a new life elsewhere. The longer an individual remains living in another place the greater the chance that they will plant roots there and not return to Seattle.

Feedback loops (Sterman 2004, Ford 2009) can be identified in the causal loop diagram by tracing each loop and counting the number of negative signs. An even number of negative signs (or no negative signs) indicates a positive feedback loop. Positive loops typically lead to exponential growth if left unchecked. One particularly important positive loop is denoted in the diagram. As the total number of individuals leaving Seattle increases, there are decreases in financial security and the livability of the city. As residents' financial security decreases and the livability of the city decreases, the "costs" of leaving Seattle also decrease, which leads to an increase in individuals deciding to leave Seattle, which in turns increases the total number of residents who have left the city. This positive feedback loop would typically lead to exponential growth in the number of residents leaving Seattle if left unchecked.

An odd number of negative signs in a causal loop circuit indicates a negative feedback, or control loop. Such control loops typically prohibit the unbridled exponential growth of positive loops. One such example of a control loop in denoted in the diagram. As more and more people decide to leave Seattle, the density is reduced, and the public is further from the hot zone. As the distance from the hot zone increases, individuals' threat assessments decrease, leading to a reduction in the perceived security gap, which in turn leads to a reduction in the number of individuals deciding to leave Seattle. This negative feedback loop acts as a control on the positive feedback loop described above; the net result is that the number of individuals leaving Seattle will ultimately asymptote long before Seattle is completely abandoned. 


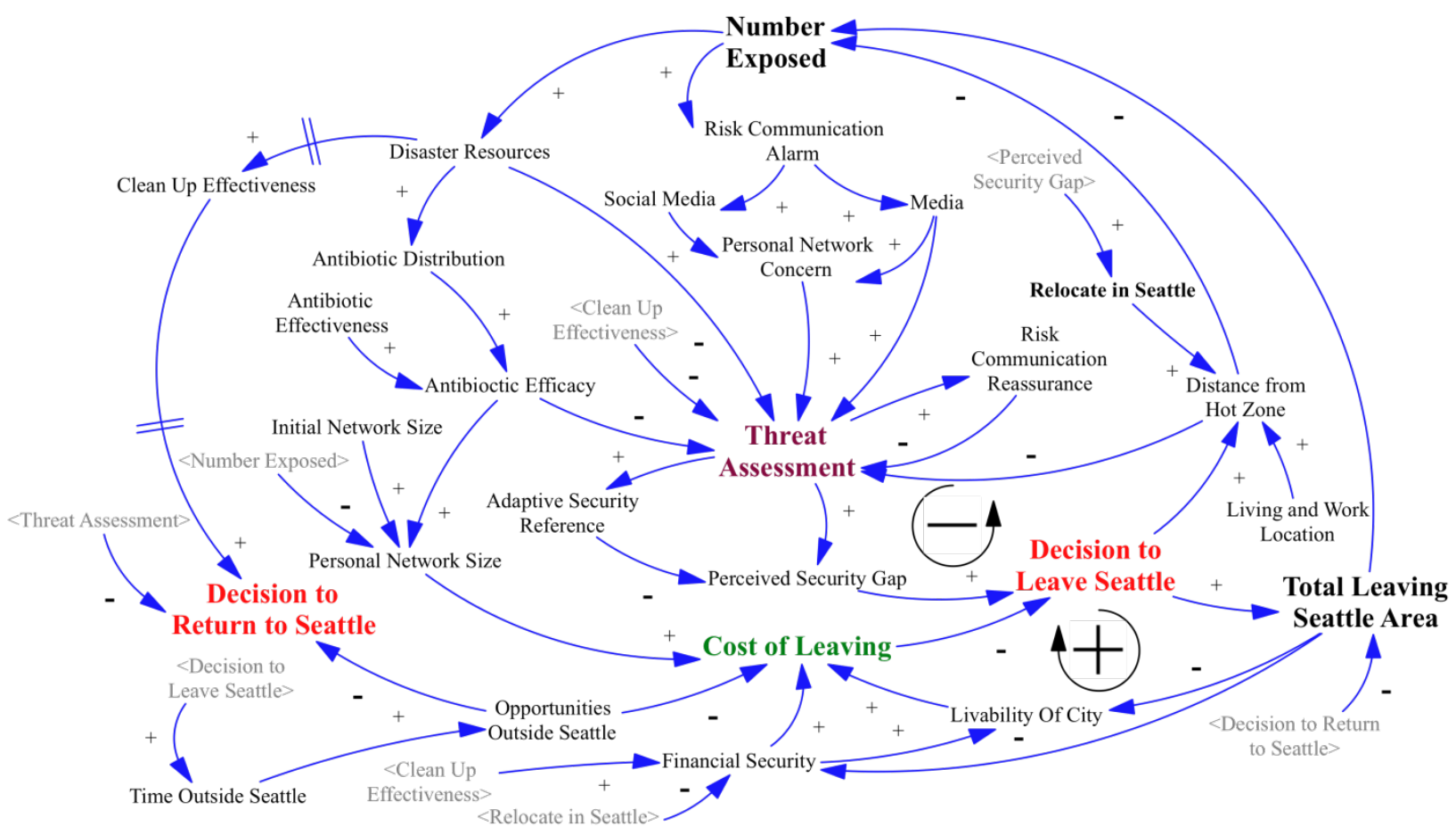

Figure 3. Causal loop diagram depicting the dynamics driving the decision to stay in, leave or return to Seattle following an anthrax attack.

\section{DISCUSSION}

We have introduced an innovative approach for assessing the influence of values and beliefs on Seattle residents' decision making in the event of an anthrax attack. By taking into account Seattle residents' priorities and uncertainties associated with decision making, policy makers are better informed about where to direct their efforts, which in turn will contribute positively to the long-term sustainability of the region. Using the scenario simulation approach, respondents were allowed to share their reactions and to engage in discussions about their emotions, beliefs and perceived decision options during the anthrax attack scenario. This design uses video simulation and group discussion to emotionally immerse respondents into the anthrax attack scenario. A critical focus of this study was on capturing the dynamic nature of respondents' reactions, including beliefs, emotions and intended actions as the post anthrax attack scenario develops over eight discrete episodes.

Our findings suggest that there are variations in the concerns of respondents over time. Initially, both the general public and business group respondents were preoccupied with the personal and health safety of themselves and their friends. The extent to which Seattle residents felt confident in their safety was conditional upon factors for which they had considerable uncertainty - anthrax exposure, infection and consequences. Consequently, they were making decisions about their safety without knowing whether the biological agent was contagious, what it meant to be infected with anthrax, or whether it was safe to go outside and seek treatment. The development of policy initiatives focused on communicating information about access to treatment and the availability of resources was found to be essential at the outset. In addition, respondents were interested in the provision of many pre-existing economic policies that, if provided soon after the event, would effectively mitigate the extent of the consequences following a disaster. For example, we found that up to three months following the attack, the general public was responsive to housing subsidies. However, at 2 years post attack they believed they would be relocated 
elsewhere and less likely to return to Seattle despite the economic incentives discussed.

Also during the immediate attack aftermath, business group respondents were conflicted about their ability to sustain business operations within the region. Should they leave the area and relocate their business, or keep operations running to the best of their ability through what is expected to be a short term disruption? Unaware of the extent and quality of decontamination protocols, business respondents were blindly making decisions about their financial stability. Again, the development of policies directed at educating the public about procedures for cleanup would help to manage the business community's expectations relative to keeping their operations in Seattle. In addition, business community respondents were responsive to the idea of receiving tax breaks and other related economic incentives shortly following the anthrax attack. If this situation were to occur, respondents believed that most companies would not have to leave the area and that businesses could work with the government to restore economic stability to the region sooner.

Over time, the focus of public and business group respondents shifted. While still preoccupied with their personal and health safety, there was increasing concern about their long-term financial stability and quality of life considerations if they were to remain in the region. Adding to uncertainties about what is "safe enough", Seattle residents were unaware of what to expect in terms of job opportunities and the impacts of the attack on daily living. Ongoing communication about how to live in post-attack Seattle, as well as the provision of financial subsidies would be beneficial, yet possibly not as impactful as immediately following the attack. When respondents were asked if they would return to Seattle (or continue to stay if they had not left), residents who never left the city were more willing to remain in Seattle and accept the need to exercise increased sensitivity to and awareness of the attack consequences. Those who had relocated were less inclined to return over time due to ongoing safety and health concerns and the lack of desire to uproot from the new home and job they had created for themselves and their families.

Similarly, among business group respondents it was believed that only businesses with the financial stability to continue amidst the crisis would likely remain and/or return to the region. Without the support afforded by economic incentives, other businesses would likely have made the decision to relocate. Once committed to such a costly endeavor, business respondents felt that they were not likely to return. Most critical for business group respondents is that post-attack policies be developed and implemented in a timely manner so that informed decisions can be made about whether or not to relocate.

Throughout the development and execution of the scenario simulation group exercises, we were challenged to maximize the realism of the simulated event and the extent to which our respondents' reactions correspond to those we would observe following an actual terrorist attack. Compared to other existing methodologies (e.g. traditional surveys with no video scenario simulation), the scenario simulation design obtains a more realistic understanding of how respondent's emotions and behavior change as the post-anthrax attack scenario unravels over time. We also found that while policy recommendations were identified at the different phases post attack, this study does not address policy implementation issues. Future research on the effects of risk signals (Slovic 1987) and gain-loss framing (Kahneman and Tversky 1979, Levin et al. 1998) on policy communication will provide additional insight into how impacted populations uncertainties can be better managed by policy makers.

To this end, the results presented in this paper are a demonstration of the insights possible from using the group scenario simulation approach to track the dynamic beliefs, emotions and intentions to act while "in the moment" of the response and recovery following a terrorist attack. Our findings suggest that characterizing public values and beliefs facilitates the creation of policies that safely and effectively influence decision making during a disaster situation as well as reduce the extent of the disaster's consequences. Government officials and emergency responders will need to take necessary steps to have policies in place prior to the actual disaster for the importance of such findings to be realized. 


\section{ACKNOWLEDGEMENTS}

This research was supported by the U. S. Department of Homeland Security through the National Center for Risk and Economic Analysis of Terrorism Events under grant number 2007-ST-061-000001 and the National Science Foundation under grant number SES-0728934. However, any opinions, findings, conclusions, and recommendations in this document are those of the authors and do not reflect views of the U. S. Department of Homeland Security or National Science Foundation. We would like to thank Steve Stein, Ann Lesperance and Mary Fordham from PNNL for their assistance in organizing the business group discussions, as well as Elizabeth Casman from Carnegie Melon University, Patrick Gurian from Drexel University and researchers from the RAND Corporation for the consultation as experts on biological contaminants. Lastly, we would like to thank Fynnwin Prager, Shelly McArdle and Jacki Chou for their support in the planning and execution of the anthrax attack scenario simulation exercise.

\section{REFERENCES}

Alhakami, A.S., and Slovic, P. (2004) A psychological study of the inverse relationship between perceived risk and perceived benefit. Risk Analysis, 14 (6) : 1085-1096.

Burns, W.J., and Slovic, P. (2007) The diffusion of fear: Modeling community response to a terrorist strike. The Journal of Defense Modeling and Simulation: Applications, Methodology, Technology 4 (4) : 1-20.

Department of the Army (1977) U.S. army activity in the U.S. biological warfare programs. Vol II. Publication DTIC B193427L. Washington: The Department.

DeSalvo, K.B., Hyre, A., Ompad, D., Menke, A., Tynes, L., and Muntner, P. (2007) Symptoms of posttraumatic stress disorder in a New Orleans workforce following Hurricane Katrina. Journal of Urban Health, 84 (2) : 142-152.

Engelberg, E., and Sjöberg, L. (2005) Perceived reality of visually mediated hazards and beliefs about risk. Applied Cognitive Psychology, 19 (7) : 899-912.

Fischhoff, B., Gonzalez, R., Small, D., and Lerner, J. (2003) Judged terror risk and proximity to the World Trade Center. Journal of Risk and Uncertainty, 26 (2-3) : 137-151.

Ford, A. Modeling the environment. 2nd Ed. Washington, D.C.: Island Press.

Giesecke, J.A., Burns, W.J., Barrett, A., Bayrak, E., Rose, A., Slovic, P., and Suher, M. (2012) Assessment of the regional economic impacts of catastrophic events: CGE analysis of resource loss and behavioral effects of a RDD attack scenario. Risk Analysis, 32 (4) : 583-600.

Howard, R. (2007) The foundations of decision analysis revisited. In W. Edwards, R. Miles, and D. von Winterfeldt (Eds.), Advances in decision analysis: From foundations to applications, 32-56. New York: Cambridge University Press.

Howard, R.A., and Matheson, J.E. (2005) Influence diagrams. Decision Analysis, 2 (3) : 127-143.

Ichinosawa, J. (2006) Reputational disaster in Phuket: the secondary impact of the tsunami on inbound tourism. Disaster Prevention and Management, 15 (1) : 111-123.

Kahneman, D., and Tversky, A. (1979) Prospect theory: An analysis of decision under risk. Econometrica, 47 (2) : 263-291.

Kortepeter, M., and Parker, G. (2009) Potential biological weapons threats. Emerging Infectious Diseases, 5 (4) : 523-527. 
Levin, I.P., Schneider, S.L., and Gaeth, G.J. (1998) All frames are not created equal: A typology and critical analysis of framing effects. Organization Behavior and Human Decision Processes, 76 (2) : 149-188.

Morrow-Jones, H.A., and Morrow-Jones, C.R. (1991) Mobility due to natural disaster: Theoretical considerations and preliminary analyses. Disasters, 15 (2) : 126-132.

Rosoff, H., John, R.S., Burns, W., and Maya, I. (2011). Scenario simulation group reactions to the aftermath of the great shake-out magnitude 7.8 earthquake, Earthquake Spectra, 27 (2): 597-614.

Rosoff, H., John, R.S., and Prager, F. (2012) Flu, risks, and videotape: Escalating fear and avoidance. Risk Analysis, 32 (4) : 729-743.

Runge, J.W. (2008) Assistant Secretary for Health Affairs, Department of Homeland Security, written testimony before the House Committee on Homeland Security, July 22, 2008.

Shachter, R.D. (1986) Evaluating influence diagrams. Operations Research, 34 (6) : 871-882.

Slovic, P. (1987) Risk perception. Science, 236 (4799) : 280-285.

Slovic, P., and Peters, E. (2006) Risk perception and affect. Current Directions in Psychological Science, 15 (6) : 322-325.

Slovic, P., Peters, E., Finucane, M., and MacGregor, D. (2005) Affect, risk, and decision making. Health Psychology, 24 (4) : 35-40.

Sjöberg, L. (1998) Worry and risk perception. Risk Analysis, 18 (1) : 85-93.

Sjöberg, L. (2002) Are received risk perception models alive and well? Risk Analysis, 22 (4) : 665-669.

Smith, B., Kay, V., Hoyt, T., and Bernard, M. (2009) Predicting the anticipated emotional and behavioral responses to an avian flu outbreak. American Journal of Infection Control, 37 (5) : 371-380.

Sterman, J. (2004) Business dynamics: Systems thinking and modeling for a complex world. Boston: Irwin/McGraw-Hill.

Tierney, K.J. (1989) The social and community contexts of disaster. In: Gist R, Lubin B, eds. Psychosocial Aspects of Disaster. Oxford, England: John Wiley \& Sons; p. 11-39.

Tierney, K.J. (1999) Toward a critical sociology of risk. Sociological Forum, 14 (2) : 215-242.

Tierney, K.J. (2007) From the margins to the mainstream? Disaster research at the crossroads. Annual Review of Sociology, 33: 503-525.

Tierney, K.J. (2008) Hurricane in New Orleans? who knew? Anticipating Katrina and its devastation. Sociological Inquiry. Special Issue: Twenty-first century disasters: Why should we care about worst cases?, 78 (2) : 179-183.

Tierney, K.J., Bevc, C., and Kuligowski E. (2006) Metaphors matter: Disaster myths, media frames, and their consequences in Hurricane Katrina. Annals of the American Academy of Political and Social Science, 604 (1) : 57-81.

Västfjäll, D., Peters, E., and Slovic, P. (2008) Affect, risk perception and future optimism after the tsunami disaster. Judgment and Decision Making, 3 (1) : 64-72.

Wardman, J.K. (2006) Toward a critical discourse on affect and risk perception. Journal of Risk Research, 9 (2) : 109-124.

Weis, C.P., Intrepido, A.J., Miller, A.K., Cowin, P.G., Durno, M.A., Gebhardt, J.S., and Bull, R. (2002) Secondary aerosolization of viable Bacillus anthracis spores in a contaminated US Senate Office. The Journal of the American Medical Association, 288 (22) : 2853-8. 
Yi Ge, Y., Xu, W., Gu, Z., Zhang, Y., and Chen, L. (2011) Risk perception and hazard mitigation in the Yangtze River Delta region, China. Natural Hazards, 56 (3) : 633-648.

\section{APPENDIX A: STUDY PARTICIPANTS}

We were interested in interacting with individuals from Seattle likely to face critical decisions following an anthrax attack. A brief survey was conducted using Qualtrics (http://www.qualtrics.com/) to identify volunteers from the Seattle public willing to participate in a scenario simulation group exercise. The survey included basic demographic questions, questions about job satisfaction and commuting, questions about satisfaction with living in Seattle and a question inquiring about the participant's interest in being paid to participate in a group discussion exercise related to homeland security. Table 1 provides a summary of the demographic data for the Seattle sample. [Note: Percentages do not always sum to 100 due to non-responses and rounding.]

\begin{tabular}{|c|c|c|}
\hline \multicolumn{3}{|c|}{ Sample Characteristics $(\mathrm{N}=423)$} \\
\hline $\begin{array}{l}\text { Demographic } \\
\text { Variable }\end{array}$ & $\begin{array}{c}\text { Variable Response } \\
\text { Category }\end{array}$ & $\begin{array}{c}\text { Percentage of } \\
\text { Sample }\end{array}$ \\
\hline \multirow{2}{*}{ Gender } & Female & $67 \%$ \\
\hline & Male & $31 \%$ \\
\hline \multirow{4}{*}{ Marital Status } & Married & $49 \%$ \\
\hline & Single & $35 \%$ \\
\hline & Divorced/Separated & $14 \%$ \\
\hline & Widow/Widower & $1 \%$ \\
\hline \multirow{5}{*}{ Race/Ethnicity } & Caucasian/White & $77 \%$ \\
\hline & Asian/Pacific Islander & $10 \%$ \\
\hline & African American/Black & $8 \%$ \\
\hline & Native American/Other & $4 \%$ \\
\hline & Hispanic & $3 \%$ \\
\hline \multirow{2}{*}{ Born in the US } & Yes & $87 \%$ \\
\hline & No & $12 \%$ \\
\hline \multirow{4}{*}{$\begin{array}{c}\text { Current } \\
\text { Employment } \\
\text { Status }\end{array}$} & Full-time & $41 \%$ \\
\hline & Unemployed/Other & $35 \%$ \\
\hline & Part-time & $15 \%$ \\
\hline & Retired & $9 \%$ \\
\hline \multirow{4}{*}{$\begin{array}{l}\text { Years Living in } \\
\text { Seattle }\end{array}$} & $15+$ Years & $54 \%$ \\
\hline & $5-14$ Years & $24 \%$ \\
\hline & $1-4$ Years & $17 \%$ \\
\hline & Less than 1 year & $4 \%$ \\
\hline \multirow{4}{*}{$\begin{array}{l}\text { Current Living } \\
\text { Situation }\end{array}$} & Renting & $50 \%$ \\
\hline & Home Owner & $39 \%$ \\
\hline & Live with Parents/Family & $6 \%$ \\
\hline & Border & $4 \%$ \\
\hline \multirow{2}{*}{$\begin{array}{l}\text { Prefer to Live in } \\
\text { Another City? }\end{array}$} & No & $54 \%$ \\
\hline & Yes & $45 \%$ \\
\hline
\end{tabular}

Table 1. Seattle public sample background and demographic breakdown 
Those respondents who expressed an interest in learning more were sent an email explaining that researchers from the University of Southern California are recruiting people to participate in a group discussion with about 8-10 other local Seattle residents to watch and react to a video simulation of an emergency situation. The flyer also explained that the purpose of the study was to learn more about their perceived uncertainties, priorities and decision making during an emergency situation and provided information about the time, location and compensation provided for their participation. Subjects were compensated \$20 per hour for a two-hour session and \$10 for transportation costs (for a total of \$50) on the day of the group simulation exercise.

In addition, researchers were interested in convening members of Seattle's business community. This subset of the Seattle population was sought out in order to understand how the personal and professional reactions of local business leaders might differ from those of the general public in the event of an anthrax attack. We contacted 21 key business organizations involved with the IBRD program about participating in a group exercise. Table 2 is a list of the organizations contacted. The selected members of the business community were contacted by phone as well as sent an email similar to that used for the general public.

\begin{tabular}{|c|c|}
\hline Industry & Organization \\
\hline \multirow[t]{5}{*}{ Real Estate } & $\begin{array}{l}\text { Building Owners and Managers Assoc, of } \\
\text { Seattle King Co. }\end{array}$ \\
\hline & CAC Real Estate Management Co., Inc. \\
\hline & Wright Runstad \& Company \\
\hline & Metzler Realty Advisors, Inc. \\
\hline & CB Richard Ellis \\
\hline \multirow[t]{12}{*}{ Critical Infrastructure } & Puget Sound Energy \\
\hline & Safeway Corporation \\
\hline & Harborview Medical Center \\
\hline & West Point Wastewater Treatment \\
\hline & Costco \\
\hline & Seattle Public Utilities \\
\hline & Seattle City Light \\
\hline & Tacoma Power \\
\hline & Unified Grocers \\
\hline & Port of Seattle \\
\hline & Port of Tacoma \\
\hline & King County Transit Metro \\
\hline \multirow[t]{4}{*}{ Insurance } & Safeco Insurance \\
\hline & PEMCO Insurance Company \\
\hline & Unigard \\
\hline & Premera Blue Cross \\
\hline
\end{tabular}

Table 2. Listing of Seattle business community organizations contacted.

\section{APPENDIX B: SCENARIO GENERATION}

We developed a scenario simulation of a deadly anthrax release by terrorists in the Seattle area based on PNNL's "Seattle-Tacoma Urban Area Anthrax Incident: Long-Term Recovery Tabletop Exercises" used as part of IBRD. PNNL's 90-day attack scenario describes a large scale anthrax release on the city of Seattle and at Fort Lewis near Tacoma killing upwards of 54,000 individuals and producing exposure symptoms in 108,000 more. The duration and details of the IBRD scenario were used during the exercise to measure self-evacuation of the Seattle-Tacoma region during the immediate aftermath of the anthrax 
attack. We extended the scenario to include possible return up to two-years following the attack. Scenario details were based on open-source research and consultation provided by experts in biological contaminants. In addition, DHS action plans related to the cleanup and recovery process following a large-scale biological attack aided in the creation of the scenario.

In the form of video news broadcasts, the scenario progresses over eight delineated episodes. A summary of the anthrax attack simulation scenario by episode is provided in Table 3. Beginning with coverage 93 hours after the simulated attack, the Secretary of Homeland Security announces that the BioWatch warning system and lab tests have confirmed the release of anthrax in Seattle. Emergency officials are recommending that residents of the Seattle area who may have been exposed begin taking a 60-day antibiotic regimen as prophylaxis. In the hours following (97 hours after the release), 14 people are reported to have lost their lives to anthrax and the number of confirmed cases of anthrax infection continues to rise rapidly. The boundaries of the areas contaminated with anthrax spores continue to be unknown; however, Downtown Seattle and Fort Lewis have been identified as the centers of two separate anthrax releases. DHS has instructed all people in the downtown area to evacuate immediately. It is estimated that the lives of up to 500,000 people are at risk of exposure to anthrax. Roughly one week after the first report of the anthrax release ( 5 and 9 days after the release), emergency responders are reporting that the death toll has risen to over 12,000 and upwards of 80,000 people are believed to be infected. Local hospitals, pharmacies and temporary distribution centers set up at police stations and schools are being completely inundated with Seattle residents seeking the antibiotic treatment. At 16 days following the release, the death toll is over 50,000 with 100,000 more infected. Morgues and crematoriums are completely overwhelmed and medics have run out of body bags. Thousands of residents continue to leave the city daily, causing massive traffic jams. Those who have decided to stay are concerned about the potential for infection created by trash and other waste piling up on city streets.

The news report then advances to one-month following the release with the announcement that the death toll has peaked at 54,000 and the rate of new infections is falling. Despite EPA efforts, home and business owners displaced by the attacks are frustrated and gathering in public forums and town hall meetings in hopes of getting answers to their many concerns about the cleanup process. Hospitals continue to be crowded with worried well and thousands are still living in the shelters constructed for those displaced from their homes. The city is starting to see signs of recovery with SEA-TAC and surrounding major airports re-opening at reduced capacity. At three months following the release, cleanup and recovery in Seattle is beginning. Federal economic recovery programs have pumped hundreds of millions of dollars into Seattle in the form of low-cost loans and assistance grants. Despite the financial support, hundreds of privately owned businesses are struggling and homeowners are discovering that property values in Seattle continue to plummet. Officials are reporting that they anticipate no additional deaths, assuming that all treated individuals follow prescribed medication regimens. However, there are concerns about the psychological impact of these attacks on Seattle residents. The scenario simulation ends two-years following the anthrax attack with reports that businesses are slowly starting to reopen following rigorous cleaning and testing by the EPA. It is estimated that complete decontamination of downtown Seattle will take anywhere between 4 to 8 years. Stress-related injuries (including posttraumatic stress disorder) and hospitalizations are higher in Seattle than any other American city. While the Federal government continues to provide mental health services for those in need, the atmosphere of Seattle remains solemn but optimistic. 


\begin{tabular}{|c|c|c|}
\hline Scene & Timeline & Summary \\
\hline 1 & $\begin{array}{c}93 \text { hours } \\
\text { after release }\end{array}$ & $\begin{array}{l}\text { Anthrax is released in Seattle and Fort Lewis near Tacoma. The BioWatch warning } \\
\text { system and lab tests confirm the attack. } 75 \text { people are infected. A } 60 \text {-day antibiotic } \\
\text { regimen is prescribed to residents of the Seattle area that may have been exposed. }\end{array}$ \\
\hline 2 & $\begin{array}{c}97 \text { hours } \\
\text { after release }\end{array}$ & $\begin{array}{l}14 \text { people have died, } 250 \text { more are infected. Up to 500,000 people have been exposed; } \\
\text { the exact boundaries of the contaminated areas are unknown, though downtown Seattle } \\
\text { and Fort Lewis near Tacoma are major centers. Residents are told to evacuate. Local } \\
\text { schools and transportation may shut down. }\end{array}$ \\
\hline 3 & $\begin{array}{c}5 \text { days after } \\
\text { release }\end{array}$ & $\begin{array}{l}\text { Local supplies of antibiotics are being depleted fast. Panic is present in hospitals and on } \\
\text { the streets. Death toll has already climbed to } 121 \text { with thousands more believed to be } \\
\text { infected. Long lines at treatment centers show no signs of improving until Federal } \\
\text { antibiotics arrive. }\end{array}$ \\
\hline 4 & $\begin{array}{l}9 \text { days after } \\
\text { release }\end{array}$ & $\begin{array}{l}\text { Death toll climbs to 3,000 with over 20,000 infections; rate of new infections is still } \\
\text { increasing. Decontamination and treatment centers have been inundated and made worse } \\
\text { by hospital closures near the downtown hotzone. Antibiotic side-effects are causing } \\
\text { concerns, some residents refusing to follow the } 60 \text {-day regimen. }\end{array}$ \\
\hline 5 & $\begin{array}{c}16 \text { days after } \\
\text { release }\end{array}$ & $\begin{array}{l}\text { The death toll is over 50,000 with } 100,000 \text { more infected. Thousands of residents leave } \\
\text { the city daily, causing massive traffic jams. New infection rate falls drastically and is } \\
\text { expected to continue falling. As the medical situation improves, infrastructure problems } \\
\text { become apparent. Decontamination begins. }\end{array}$ \\
\hline 6 & $\begin{array}{l}\text { One month } \\
\text { after release }\end{array}$ & $\begin{array}{l}\text { Death toll has peaked at 54,000 with the rate of new infections falling. Hospitals remain } \\
\text { crowded. Thousands live in shelters. Local home and business owners organize to } \\
\text { demand answers from the EPA. Areas of the city evacuated during the attacks are seeing } \\
\text { rises in burglaries. SEA-TAC airport reopens. }\end{array}$ \\
\hline 7 & $\begin{array}{l}\text { Three } \\
\text { months after } \\
\text { release }\end{array}$ & $\begin{array}{l}\text { Terrorists responsible for the attack are apprehended, Seattle focuses on cleanup and } \\
\text { recovery. The Federal government has funneled millions of dollars towards recovery in } \\
\text { Seattle though many businesses still struggle. Property values in the region have fallen } \\
\text { steadily since the attack. No additional deaths are expected. }\end{array}$ \\
\hline 8 & $\begin{array}{l}\text { Two years } \\
\text { after release }\end{array}$ & $\begin{array}{l}\text { Slow business reopenings following rigorous cleaning and testing by the EPA. Timelines } \\
\text { for full decontamination range from } 4 \text { to } 8 \text { years. Federal economic aid programs } \\
\text { continue. Stress-related problems (including PTSD) affect Seattle. Stress counseling and } \\
\text { revitalization programs are paid for by the Federal government. }\end{array}$ \\
\hline
\end{tabular}

Table 3. Anthrax Attack simulation scenario summary by scene

\section{APPENDIX C: PROCEDURE}

\section{Study 1 - Seattle Public Groups}

In December of 2010, scenario simulation groups were organized using University of Washington students and Seattle residents recruited through the previously described demographics survey. Over 6 sessions there were a total of 26 participants, of which 12 were graduate students from the University of Washington and the remaining 14 were members of the Seattle public. The two hour sessions opened with a brief overview of the study and what to expect from the video episodes. Participants were instructed to imagine they were experiencing the anthrax attack and told to provide their reactions to each episode as if the event were truly taking place. Realistic notions about public response, needs and decision making 
were captured by what respondents conveyed as being important objectives and considerations as the aftermath of the crisis developed over time. The eight video episodes were shown one at a time, allowing for researcher initiated questions and discussion among group members between episodes. Specific questions were asked about change of routine, plans for evacuation, emotional responses, and the conflicting personal objectives that participants might experience throughout the crisis and recovery process.

\section{Study 2 - Business Group Exercises}

In January of 2011 members of the Seattle business community were convened to participate in the scenario simulation group exercise. A total of 6 business contacts attended 3 separate group sessions. The structure of the group exercises followed the same format used for the public sessions. The two hour sessions opened with a brief overview of the study purpose and group procedures. Subsequently, participants were taken through the videos and asked to comment after each episode about what they were feeling and thinking, particularly with respect to their company's likely decision making related to operations following the simulated terrorist attack. Emphasis was placed on questions about their company policies immediately following an attack - for instance, if located outside the attack sites, would employees be expected to continue working? would the company supply antibiotics on site? Another area of inquiry was anticipated long-term strategies taken by a company if the region's economy were to suffer significantly. Would relocation of company offices be an option? What effect would government economic incentives have on these decisions? 